\title{
Creating a Sense of Community for Distance Education
}

\section{Simon Stephenson ${ }^{1}$}

Bahçeşehir University

\begin{abstract}
This study used a qualitative analysis approach to review and organize thematically the findings of 29 studies related to sense of community in online learning. The purpose of this paper was to identify what the main themes were in the literature and to develop some practical applications as a result of the study as well as suggest areas for future research. The main themes identified were the importance of early establishment of behaviours and activities that facilitate community, the role that the instructor should play, the importance of developing social presence and social cohesion amongst learners.

Submitted

02 August 2019

Revised

20 March 2019

Accepted

14 June 2019

Keywords:

Distance Education,

Sense of Community,

Systematic Review.
\end{abstract}

\section{Suggested Citation:}

Stephenson, S. (2019). Creating a Sense of Community for Distance Education, International Journal of Academic Research in Education, 5(1), 1-8. DOI: 10.17985/ijare.524225

\footnotetext{
${ }^{1}$ Bahçeşehir University, simonsalvatore.stephenson@sfl.bau.edu.tr
} 


\section{INTRODUCTION}

Distance education can be defined as planned teaching and learning where teaching and learning occur at different locations and require certain technologies to enable communication (Moore \& Kearsley, 2012). It has become a more and more prevalent form of education throughout the world, with more than six million students and growing in the US alone taking distance education courses (Wellesley, 2017).

Sense of community is the feeling of belonging, involvement and value amongst a group (McMillan \& Chavis, 1986). It is especially important for distance education as both learners and teachers may feel a sense of isolation, and a strong sense of community overcomes this and leads to a more successful learning experience (McElrath \& McDowell, 2008). A sense of community has been shown to both "enhance student engagement and improve learning outcomes in online courses," (Gallagher-Lepak, Reilly \& Killion, 2009, p. 133). In fact, students with a lower sense of community often perceive that they are learning less, even if this is not the case (Moore, 2014). Unfortunately, the sense of community that develops in regular face to face classes is often noticeably absent in distance education courses (Sadera, Robertson, Song, \& Midon, 2009).

There is a noticeable absence of clear, detailed approaches supported by peer reviewed studies that educators and institutions might follow in order to promote a sense of online community (Sun \& Chen, 2016). Therefore, in this paper a systematic review of the literature is presented which was designed to review, collect and organize what findings are currently available into the key components and practices for creating a sense of community in distance education. This was done in order to provide practical implications and to suggest areas for further research. As stated by McElrath and McDowell, "distance education instructors, administrators, and students need strategies that build community in online courses," (2008, p. 125).

\section{Purpose of the study}

The study aims to contribute to the literature by addressing the following research question: How can a sense of community best be created in distance education courses?

\section{METHOD}

\section{Data Source Search Criteria and Methodology}

For this review, a systematic methodology was employed to select literature sources in order to identify how a sense of community can be created in distance education. The search was confined to papers published from 2008 onwards to the present day. The databases used were Google Scholar, and Education Resources Information Center (ERIC), as the two combined include a wide range of papers related to the topic. The key words and terms used in the search function were "create / establish / sense of community," and "online / distance education / learning." In this study distance education and online education will be used interchangeably.

All articles found based on these criteria and deemed relevant to the research topic were examined and a database was created. At the end of this process the database contained more than 60 articles. The database summarized the research questions, participants, data collection methods, data analysis and study results of each article. It also contained comments about the relevance and usefulness of each study to the research question. From this database 29 articles were selected. Only those which were scientific, peer reviewed, empirical studies from journals in related fields and published in English were chosen. The chosen articles were those which most clearly contain concepts, theories and data related to online learning communities, from all the articles reviewed. 


\section{Data Analysis}

As the literature was reviewed, themes in the development of sense of community began to emerge and were noted. These themes were organized into four distinct areas which were found to be the most significant for the establishment of a sense of community in online learning, due to the frequency of their being mentioned in the 29 reviewed studies (although there is some degree of overlap between them). They are partially based on the community of inquiry framework which divides the educational experience into social presence, cognitive presence and teaching presence (Garrison, Anderson \& Archer, 2000). The organized themes that have emerged from the literature are early establishment, social presence, social cohesion, and the role of the instructor. Both collaboration and communication were initially considered as potential options for their own categories due to the frequency of their being mentioned in the literature. However, each were mentioned so often in all findings in the literature that it was impossible to separate them from the other four induced themes.

\section{FINDINGS}

\section{Early Establishment}

Of the studies reviewed, many found that one of the most essential parts of establishing a sense of community in online learning is starting and setting the tone for the course (Byrd, 2016; JohnstoneDodge, Bowen, Calley \& Peterson, 2014; Menchaca \& Bekele, 2008; Moore, 2014; Shackelford \& Maxwell, 2012). The initial atmosphere is very important and should be open and feel safe for the students, allowing them to express themselves and feel free to communicate. This atmosphere will allow for the development of social presence (discussed in detail in the next section of the review) and help connect students to each other and help the instructor to establish a community (Johnstone-Dodge et al., 2014).

There are several practical methods suggested by the literature for establishing and developing a sense of community from the onset of the course. Shackelford and Maxwell found in their 2012 study on sense of community that introductions and the students having the opportunity to share personal experiences was an important part of this. As well as introductions, Moore (2014) found in his study that "introductory activities such as discussion forum ice-breakers, orientation videos, and testimonials from past successful students are all ways to help set the foundation for a classroom community," (p. 24). Another finding of several studies is that face to face interaction at the start of the course can have a positive impact on sense of community (Byrd, 2016; Menchaca \& Bekele, 2008). This could be an orientation course or team building activities. Menchaca and Bekele especially found that both students and course teachers strongly supported face to face interaction at the start of online courses.

\section{Social Presence}

One of the three key aspects of the Community of Inquiry framework is social presence and according to Boston, Diaz, Gibson, Ice, Richardson and Swan (2009), it is the foundation for collaborative learning in the online environment. Social presence is the feeling an online learner has of being with other real people and being able to project themselves and feel that they are recognized, according to Boston et al., who found that "feelings of community and social presence may be considered to be strongly connected to each other," (p. 76). The technology used often is the main focal point for studies of online education, but it is the people who make online education work. When learners in these online environments cultivate an online social presence they "achieve meaningful interactions, establish and maintain relations, and create productive social systems in these environments," (Kehrwald, 2008, p. 99). In online learning "a web of relationships between individuals" is an important part of developing learning communities (Drouin \& Vartanian, 2010, p. 148). However, students who have a poor grasp of the required technology may have a lower sense of social presence (Bolliger \& Halupa, 2012).

While the idea that social presence is an important aspect for a sense of community online is clearly supported by the literature (Ke, 2010), there are far fewer studies that provide conclusive data on how to go about establishing or facilitating that social presence. Gray and Tobin (2010) suggest that encouraging students to interact, communicate and collaborate asynchronously is of central importance. Young and 
Bruce suggested as a result of their 2011 study that "embedding the use of technology designed for connecting, such as Facebook, twittering and blogging, might increase the social presence of all students," (p. 226). Social presence can also be developed through activities where students have the opportunity to get to know each other and find commonalities (Gallagher-Lepak, Reilly \& Killion, 2009; Robinson \& Hullinger, 2008), especially through game like activities which can further develop social presence and sense of community (Shackelford \& Maxwell, 2012).

\section{Social Cohesion}

Another theme identified in the review as an essential element of online learning communities was sense of cohesion. As stated in their 2009 study, "group cohesion refers to the development of a group identity and the ability of participants in the learning community to collaborate meaningfully," (Boston et al., p. 68). On the factors which underlie a sense of community, Abedin, Daneshgar \& D'Ambra (2010) concluded that social presence and social cohesion were the two most important.

One of the aspects of distance education that can be detrimental to community is the feelings students can have of isolation, as a result of geographical distance and sense of psychological distance (Lee \& Choi, 2011; Pigliapoco \& Bogliolo, 2008). According to the findings of Rakes \& Dunn (2010), this geographical distance which is present in distance learning can be overcome primarily by participation, open communication and collaboration. Relating back to the findings grouped into the theme of early establishment, it is important to foster these ideas early on and the course should be designed in such a way as to promote these elements. The design and organization of the course, as well as the learning technology used, can lead to students having a stronger sense of each other, more frequent communication and a resulting feeling of cohesion (Abedin et al, 2010; Johnstone-Dodge et al., 2014). Aykol and Garrison also found that "collaborative activities increased students' sense of belongingness to the group which led them from an individual perspective to a group perspective," (2008, p. 16). Another study, by Cox and Cox (2008) suggested that discussion boards could be used to help facilitate this kind of collaborative learning environment, while at the same time encouraging students to get to know each other. The research of Wise, Saghafian and Padmanabhan (2012) added to this with their findings that if learners were given roles to play then their participation in discussion boards would be higher.

Social cohesion is also affected by group size in online learning (Moore, 2014; Robinson \& Hullinger, 2008; Shaw, 2013). Unsurprisingly, it was found that smaller group sizes lead to a greater sense of cohesion and community (Moore, 2014). In her 2013 study on group sizes in online learning, Shaw found that group sizes did not actually affect performance, but it did significantly impact participation. The research of Robinson and Hullinger (2008) presented that smaller groups provided more opportunity for communication and synthesis of ideas for meaningful learning, which aids in building learning communities.

Other factors that affect social cohesion are learner characteristics like age, gender and marital status (Abedin et al, 2010), and shared religious beliefs (Bottom, Ferrari, Matteo \& Todd, 2013).

\section{Role of the Instructor}

Perhaps the most important part of all for developing an online community is the role the instructor plays. It was one the most frequently cited facilitators of community development in the literature and many studies supported the findings of Correia and Davis that "the teacher may be viewed as the keystone species of the classroom ecology," (2008, p. 290). In a study of online teaching for adults, Ke stated that "teaching presence should be the catalyst that initiates the community development process" (2010, p.818). Sher further supported this with his 2010 study which found that the instructor had a significant role in fostering positive interaction and community development between students.

Several studies presented findings on the attributes of teachers that aided the development of a sense of community (Yang, Yu, Chen \& Huang, 2014). Johnstone-Dodge et al. (2014) indicated from their research that "well-educated and enthusiastic faculty members are central to facilitating development of an online learning community," (p. 1320). Menchaca et al., on the other hand, found that it was the competence of 
the instructors that was the most critical factor, especially regarding their knowledge of the educational technology used in the online lessons (2008). It is also clear from the literature that training, support and professional development is an important component for faculty to be able to create a sense of community for distance classes (Boling, Krinsky, Saleem \& Stevens, 2012; Young \& Bruce, 2011). This is something which may be overlooked, as illustrated by Johnstone-Dodge et al.'s findings in their study that $43 \%$ of the teachers in their sample had not received any prior training for online lessons (2014).

Implications from the literature about what teachers might actually do to facilitate a sense of community amongst learners include maintaining a visible presence and providing structure and modelling for online behavior (Kerwald, 2008; Lear, Isernhagen, LaCost, \& King 2009). According to Boston et al. (2009), instructors might also comment on posts on the discussion board, intervene during discussions to keep them moving in the right direction, and try to engage students who are inactive. Brindley, Blaschke and Walti (2009) found that instructors could cultivate a positive community by allowing students to choose their own groups or partners and topics. Referring to communicative and collaborative behaviour, Brindley et al. also found that teachers can "model, discuss, and reinforce these elements in the main conference, helping students to prepare for smaller, more intense group learning experiences. If students develop relationships with their peers early, they can build on these relationships in group work," (p. 13).

\section{DISCUSSION \& CONCLUSION}

\section{Summary}

There have been an abundance of studies that have supported the connection between student success in online learning, social presence, social cohesion, the role of the instructor and early establishment of classroom practices that promote community. These factors play an important role in overcoming the sense of aloneness that can arise as a result of the geographic distance between students and the disconnect found from interacting through a computer interface. With the right course setup in place and establishment of a communicative and collaborative atmosphere and behaviours, learners can develop the necessary sense of being with others and being part of the cohesive community that is conducive of a successful online learning environment.

\section{Study Limitations and Further Research}

One recent review of the literature on effective practices in online education found that while many studies emphasize the importance of establishing a community, most did not elaborate with any significant detail or with much supporting research on an "effective and detailed means, approaches, and technologies that could be used to achieve that objective," (Sun \& Chen, 2016, p. 171). Several studies and literature reviews provide suggested guidelines for creating a sense of community in online learning (Brindley et al., 2009; Yuan \& Kim, 2014), but further research needs to be conducted to collect data on the efficacy of those guidelines and indeed the findings in this study. Future research could also be done connecting the Community of Inquiry framework with online learning, with a specific focus on developing sense of community amongst learners. There is also seemingly a lack of studies done on the cognitive aspect of the Community of Inquiry structure in relationship to sense of community. Further research could be conducted on the cultural background of the instructor and the effect that has on community, also suggested by Baturay in her study on sense of community and perceived learning (2011).

There is an abundance of research on what practices produce effective results, but somewhat of a gap on practices to create community. As stated by Gallagher-Lepak et al. (2009), it is "essential to build the body of knowledge around strategies to enhance sense of community," (p. 143).

\section{Implications and Recommendations}

The following recommendations can be applied by instructors in online educational settings as a result of the findings in this study. 
1. Early Establishment: if possible a face to face meeting for students should be arranged at the start of the course. An atmosphere of open communication and collaboration should be fostered and students should get a chance to get to know each other and share personal details through ice breakers and warm up activities.

2. Social Presence: students should always be encouraged and motivated to participate and make their voices heard. Activities should be designed that encourage students to learn about each other's ideas and beliefs, especially game like activities. Technology like Facebook or Twitter can be embedded into the course design to facilitate social presence.

3. Social Cohesion: group sizes should be kept small and class sizes too if it is feasible. The course should be designed in a way to encourage frequent communication amongst learners and discussion boards are one effective way of doing this, especially if students are assigned roles.

4. Role of the Instructor: it is essential for institutions to support instructors with training and development for online teaching. If possible, teachers who are enthusiastic, energetic and competent users of teaching technology should be selected to teach online courses. Instructors must take an active role in facilitating a sense of community by modelling desired behaviour, encouraging participation and communication and setting up collaborative tasks for learners.

\section{References}

Abedin, B., Daneshgar, F., \& D’Ambra, J. (2010). Underlying Factors of Sense of Community in Asynchronous Computer Supported Collaborative Learning Environments. Journal of Online Learning and Teaching, 6(3), 585-596.

Akyol, Z., \& Garrison, D. (2008). The Development of a Community of Inquiry over Time in an Online Course: Understanding the Progression and Integration of Social, Cognitive and Teaching Presence. Journal of Asynchronous Learning Networks, 12(3-4).

Correia, A., \& Davis, N. (2008). Intersecting communities of practice in distance education: the program team and the online course community. Distance Education, 29(3), 289-306.

Baturay, M. H. (2011). Relationships among sense of classroom community, perceived cognitive learning and satisfaction of students at an e-learning course. Interactive Learning Environments, 19(5), 563-575.

Boling, E., Krinsky, M., Saleem, H., \& Stevens, M. (2012). Cutting the distance in distance education: Perspectives on what promotes positive, online learning experiences. Internet and Higher Education, 15, 118-126.

Bolliger, D. U., \& Halupa, C. (2012). Student perceptions of satisfaction and anxiety in an online doctoral program. Distance Education, 33(1), 81-98.

Boston, W., Díaz, S., Gibson, A., Ice, P., Richardson, J., \& Swan, K. (2009). An Exploration of the Relationship Between Indicators of the Community of Inquiry Framework and Retention in Online Programs. Journal of Asynchronous Learning Networks, 13(3), 67-83.

Bottom, T. L., Ferrari, J. R., Matteo, E. \& Todd N.R. (2013). Predicting school sense of community: Students' perceptions at two Catholic universities. Journal of Prevention and Intervention in the Community, 41, 4-14.

Brindley, J., Blaschke, L. M., \& Walti, C. (2009). Creating effective collaborative learning groups in an online environment. The International Review of Research in Open and Distributed Learning, 10 (3), 118. 
Byrd, J. (2016). Understanding the Online Doctoral Learning Experience: Factors that Contribute to Students' Sense of Community. The Journal of Educators Online, 13(2), 102-135.

Cox, B., \& Cox, B. (2008). Developing interpersonal and group dynamics through asynchronous threaded discussions: The use of discussion board in collaborative learning. Education, 128(4), 553-565.

Gallagher-Lepak, S., Reilly, J., \& Killion, C. (2009). Nursing student perceptions of community in online learning. Contemporary Nurse: A Journal for the Australian Nursing Profession, 32(1), 133-146.

Garrison, D. R., Anderson, T., \& Archer, W. (2000). Critical inquiry in a text-based environment: Computer conferencing in higher education. The Internet and Higher Education, 2(2-3), 87-105.

Gray K, Tobin J. (2010) Introducing an online community into a clinical education setting: a pilot study of student and staff engagement and outcomes using blended learning. Biomed Cent Med Educ, 10(6):9.

Johnstone-Dodge, V., Bowen, D., Calley, K., \& Peterson, T. (2014). A Faculty Development Course to Enhance Dental Hygiene Distance Education: A Pilot Study. Journal of Dental Education, 78(9), 13191330.

Ke, F. (2010). Examining online teaching, cognitive, and social presence for adult students. Computers \& Education, 55, 808-20.

Kehrwald, B. (2008). Understanding social presence in text-based online learning environments. Distance Education, 2(1), 89-106.

Lear, J., Isernhagen, J., LaCost, B., \& King, J. (2009). Instructor Presence for Web-Based Classes. Delta Pi Epsilon Journal, 51(2), 86-98.

Lee, Y., \& Choi, J. (2011). A review of online course dropout research: Implications for practice and future research. Educational Technology Research and Development, 59, 593-618.

McElrath, E., \& McDowell, K. (2008). Pedagogical Strategies for Building Community in Graduate Level Distance Education Courses. MERLOT Journal of Online Learning and Teaching, 4(1), 117-127.

McMillan, D., \& Chavis, D. (1986). Sense of community: A definition and theory. Journal of Community Psychology, 14, 6-23.

Menchaca, M., \& Bekele, T., (2008). Learner and instructor identified success factors in distance education, Distance Education, 29(3), 231-252

Moore, M. G., \& Kearsley, G. (2012). Distance education: A systems view of online learning. Belmont, CA: Wadsworth Cengage Learning.

Moore, R. (2014). Importance of Developing Community in Distance Education Courses. TechTrends, 58(2), 20-24.

Pigliapoco, E., \& Bogliolo, A. (2008). The effects of psychological sense of community in online and faceto-face academic courses. International Journal of Emerging Technologies in Learning, 3, 60-69.

Rakes, G. C., \& Dunn, K. E. (2010). The impact of online graduate students' motivation and self regulation on academic procrastination. Journal of Interactive Online Learning, 9(1), 78-93.

Robinson, C. C., \& Hullinger, H. (2008). New benchmarks in higher education: Student engagement in online learning, Journal of Education for Business, 2, 101-108.

Sadera, W., Robertson, J., Song, L., \& Midon, M. (2009). The Role of Community in Online Learning Success. MERLOT Journal of Online Learning and Teaching,5(2). 
Shackelford, J., \& Maxwell, M. (2012). Sense of Community in Graduate Online Education: Contribution of Learner to Learner Interaction. The International Review of Research in Open and Distributed Learning, 13(4), 228-249.

Shaw, R. (2013). The relationships among group size, participation, and performance of programming language learning supported with online forums. Computers and Education, 62(C), 196-207.

Sher, A. (2009). Assessing the relationship of student-instructor and student-student interaction to student learning and satisfaction in web-based online learning environment. Journal of Interactive Online Learning, 8(2), 102-120.

Sun, A., \& Chen, X. (2016). Online Education and Its Effective Practice: A Research Review. Journal of Information Technology Education: Research, 15, 157-190.

Wellesley. (2017, May 2). New Study: Over Six Million Students Now Enrolled in Distance Education. Retrieved from https://onlinelearningconsortium.org/news_item/new-study-six-million-studentsnow-enrolled-distance-education/

Wise, A., Saghafian, M., \& Padmanabhan, P. (2012). Towards more precise design guidance: Specifying and testing the functions of assigned student roles in online discussions. Educational Technology Research and Development, 60, 55-82.

Yang, J., Yu, H., Chen, S., \& Huang, R. (2014). Strategies for Smooth and Effective Cross-Cultural Online Collaborative Learning. Journal of Educational Technology \& Society, 17(3), 208-221.

Young, S., \& Bruce, M. A. (2011). Classroom community and student engagement in online courses. Journal of Online Learning and Teaching, 7(2), 219.

Yuan, J., \& Kim, C. (2014). Guidelines for facilitating the development of learning communities in online courses. Journal of Computer Assisted Learning, 30, 220-232. 